\title{
Early release of glycogen phosphorylase in patients with unstable angina and transient ST-T alterations
}

Johannes Mair, Bernd Puschendorf, Jörn Smidt, Peter Lechleitner, Franz Dienstl, Franz Noll, Ernst-Georg Krause, Georg Rabitzsch

\begin{abstract}
Objective-To determine whether transient ST-T alterations in patients with unstable angina are associated with an increase in plasma glycogen phosphorylase BB concentrations on admission to hospital.
\end{abstract}

Design-Prospective screening of patients with unstable angina for markers of myocardial cell damage.

Setting-Accident and emergency department of university hospital.

Patients-48 consecutive patients admitted for angina pectoris (18 with transient ST-T alterations). None of the patients had acute myocardial infarction according to standard criteria.

Main outcome measures-Creatine kinase and creatine kinase $M B$ activities, creatine kinase $\mathrm{MB}$ mass concentration, and myoglobin, cardiac troponin $T$, and glycogen phosphorylase BB concentrations on admission.

Results-All variables except for creatine kinase and creatine kinase $\mathrm{MB}$ activities were significantly higher on admission in patients with unstable angina and transient ST-T alterations than in patients without. However, glycogen phosphorylase BB concentration was the only marker that was significantly $(p=0.0001)$ increased above its discriminator value in most patients (16). In the 18 patients with transient ST-T alterations creatine kinase $M B$ mass concentration and troponin $T$ and myoglobin concentrations were significantly $(p=0.0001)$ less commonly increased on admission (in five, three, and two patients, respectively).

Conclusions-The early release of glycogen phosphorylase BB may help to identify high risk patients with unstable angina even on admission to an emergency department. Glycogen phosphorylase BB concentrations could help to guide decisions about patient management.

\section{(Br Heart f 1994;72:125-127)}

Glycogen phosphorylase is the key enzyme of glycogenolysis and has three main isoenzymes: BB (brain), MM (muscle), and LL (liver). ${ }^{1}$ The isoenzymes are encoded by three distinct genes and differ in their functional and immunological properties, ${ }^{12}$ which makes it possible to develop specific immunoassays.
Glycogen phosphorylase BB (molecular weight $96000 \mathrm{kDa}$ as a monomer) is the predominant isotype in human myocardium where it occurs alongside the MM subtype. ${ }^{3}$ The release of glycogen phosphorylase from injured myocardium may reflect the burst in glycogenolysis initiated during acute myocardial ischaemia. ${ }^{4}$ This is supported by a rapid increase in serum concentrations of glycogen phosphorylase $\mathrm{BB}$ in patients with acute myocardial infarction before concentrations of creatine kinase, creatine kinase $\mathrm{MB}$, myoglobin, and cardiac troponin $T$ increase. ${ }^{5}$ Unstable angina, however, ranges from no myocardial cell damage to non- $Q$ wave myocardial infarction. Myocardial ischaemia induces glycogenolysis and may lead to a transient loss of integrity of the plasma membrane, with a subsequent leakage of soluble cytosolic proteins in more severe cases. ${ }^{6} \mathrm{We}$ therefore investigated whether glycogen phosphorylase $\mathrm{BB}$ is also released early from the myocardium - that is, on admission to the emergency department-in patients presenting with unstable angina and transient ST-T alterations.

\section{Patients and methods}

PATIENTS

The study population consisted of 48 consecutive patients ( 32 men, 16 women, mean age 63.7 (SD 10.4) years) who were admitted to the emergency department of the department of internal medicine (University Hospital of Innsbruck, Austria) for typical symptoms of angina pectoris. The average delay from the onset of chest pain to admission was $4 \cdot 6(4 \cdot 4)$ hours (range 1-22 hours). In all patients acute myocardial infarction was ruled out retrospectively from standard criteria of the World Health Organisation. ${ }^{7}$ Patients with a history of recent stroke, myocardial infarction documented within the previous two weeks, valvar heart disease, or cardiomyopathy were excluded.

Standard 12 lead electrocardiography was performed routinely at the time of admission, and recordings were repeated for several times during the hospital stay. All patients were given routine antianginal treatment that included nitrates, $\beta$ blockers, calcium channel blockers, aspirin, and heparin as needed. The electrocardiograms were evaluated blindly for evidence of reversible myocardial ischaemia, defined as transient ST elevation ( $\geqslant 0.1 \mathrm{mV})$, ST depression ( $\geqslant 0.1 \mathrm{mV}$ ), and $\mathrm{T}$ inversion in at least two contiguous leads of a standard 
12 lead electrocardiogram. Patients were divided into two groups according to the presence of transient ST-T alterations at presentation. ${ }^{8}$ Neither group differed significantly according to age, sex, or delay $(p \geqslant 0 \cdot 27)$. On admission a single blood sample was collected in all patients for measurement of creatine kinase and creatine kinase MB activities, creatine kinase $\mathrm{MB}$ mass concentrations, and concentrations of myoglobin, cardiac troponin $\mathrm{T}$, and glycogen phosphorylase $\mathrm{BB}$. Creatine kinase and creatine kinase $\mathrm{MB}$ activities were repeatedly measured during the hospital stay to exclude acute myocardial infarction.

\section{LABORATORY ANALYSIS}

Creatine kinase and creatine kinase MB activities were measured without delay with Merck test kits (Darmstadt, Germany). Creatine kinase $\mathrm{MB}$ activities were measured by immunoinhibition. Blood samples for measurement of all other variables were immediately centrifuged, and the plasma was stored at $-20^{\circ} \mathrm{C}$ until analysis. Myoglobin concentration was measured by immunoturbidimetry (Behringwerke AG, Marburg, Germany); creatine kinase $M B$ mass concentrations (Abbott, North Chicago, USA) and cardiac troponin $\mathrm{T}$ concentrations (Boehringer Mannheim, Mannheim, Germany) were measured by enzyme immunoassays as previously described. $^{9-11}$ Glycogen phosphorylase BB concentration was determined by using a recently developed specific immunoenzymometric assay; this assay does not crossreact with liver or skeletal muscle isophosphorylase. ${ }^{12}$ The upper limit of the reference interval (discriminator value) of glycogen phosphorylase BB with this assay was $5 \mu \mathrm{g} / 1 .{ }^{13}$

\section{STATISTICS}

All results are expressed as means (SD) except when stated otherwise. $\chi^{2}$ Tests (with Yates's correction for continuity) and $t$ tests (two tailed) were used for statistical analysis. $P$ values $<0.05$ were considered to be significant.

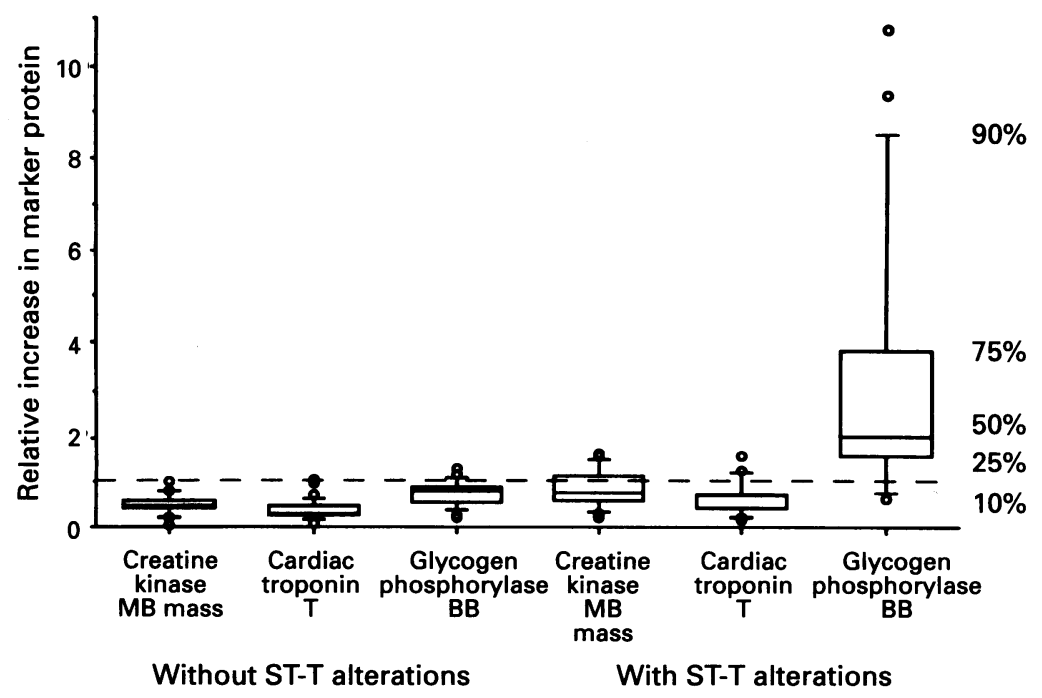

Box plots of glycogen phosphorylase isoenzyme $B B$ concentration, creatine kinase $M B$ mass concentration, and cardiac troponin $T$ concentration in patients with unstable angina on admission to emergency department. Broken line shows discriminator value of each variable.

\section{Results}

On admission to the emergency department all variables except for creatine kinase and creatine kinase $M B$ activities were significantly $(p \leqslant 0.04)$ higher in patients with transient ST-T alterations $(n=18)$. In these patients, however, creatine kinase $\mathrm{MB}$ mass concentration and myoglobin and cardiac troponin $T$ concentrations were still within the reference range in most patients. Myoglobin concentration was increased in two patients, cardiac troponin $T$ concentration in three, and creatine kinase $\mathrm{MB}$ mass concentration in five. By contrast, glycogen phosphorylase BB was significantly $(p=0.0001)$ more commonly increased in patients with transient ST$T$ alterations than all other biochemical markers tested. It was the only marker that was not only significantly higher $(p=0.0001)$, but also increased above its discriminator value in most patients even on admission to the emergency department ( $n=16$; figure). Myoglobin was not included in the figure because concentrations were above the detection limit $(50 \mu \mathrm{g} / \mathrm{l})$ in only some of the patients with ST-T alterations and below the limit in all patients without electrocardiographic changes.

\section{Discussion}

An increase in creatine kinase $\mathrm{MB}$ mass concentration and in myoglobin and cardiac troponin $T$ concentrations in a subgroup of patients with unstable angina has been previously described in serially collected blood samples during hospital admission. ${ }^{14-17}$ We found an early release of glycogen phosphorylase BB into blood in patients with unstable angina and transient ST-T alterations. In these patients glycogen phosphorylase $\mathrm{BB}$ was the only marker that was increased above its discriminator value in most of them on admission to the emergency department. The average delay from the onset of chest pain to admission was about 4.5 hours.

The biochemical basis for the rapidity with which glycogen phosphorylase $\mathrm{BB}$ is released after myocardial ischaemia is probably its function as a key enzyme of glycogenolysis. In the myocardium glycogen phosphorylase BB exists in association with glycogen and the sarcoplasmic reticulum, forming a macromolecular complex. ${ }^{18}$ During myocardial ischaemia this complex is broken down ${ }^{19} 20$ and glycogen phosphorylase BB is released into the sarcoplasma, which results in a large soluble cytosolic pool of the enzyme and a high concentration gradient between the sarcoplasma and the extracellular space. In cases of severe but reversible myocardial ischaemia the permeability of the plasma membrane is simultaneously altered so that soluble proteins can diffuse out of myocytes and be detected in blood as well. ${ }^{6}$ In addition, postmortem studies show that microinfarcts often precede myocardial infarction and sudden death in patients with unstable angina. ${ }^{2122}$ Unstable angina is a critical phase of ischaemic heart disease. The early release of glycogen 
phosphorylase may help to identify high risk patients, even on admission to the hospital, and concentrations of the BB isoenzyme could help to guide decisions about patient management.

1 Newgard CB, Hwang PK, Fletterick RJ. The family of glycogen phosphorylases: structure Rev Biochem Mol Biol 1989;24:69-99.

2 Newgard CB, Littmann DR, Genderen C, Smith $M$ Fletterick RJ. Human brain glycogen phosphorylase: cloning sequence analysis, chromosomal mapping, tissue expression and comparison with the human liver and muscle isoenzymes. $\mathcal{F}$ Biol Chem 1988;263:3850-7.

3 Kato K, Shimizu A, Kurobe N, Takashi M, Koshikawa T. Human brain-type glycogen phosphorylase: quantitative ocalization in human tissues determined with an immunoassay system. $\mathcal{F}$ Neurochem 1989;52:1425-32.

4 Michael LH, Hunt JR, Weilbaecher D, Perryman MB, Roberts R, Lewis RM, et al. Creatine kinase and phos-
phorylase in cardiac lymph: coronary occlusion and reperfusion. Am f Physiol 1985;248:H350-9.

5 Rabitzsch G, Mair J, Lechleitner P, Noll F, Hofmann U, Krause EG, et al. Isoenzyme BB of glycogen phosphorylase $b$ and myocardial infarction (letter). Lancet 1993;241:1032-3.

6 Piper HM, Schwartz P, Spahr R, Hütter JF, Spieckermann PG. Early enzyme release from myocardial cells is not due to irreversible cell damage. $₹ \mathrm{Mol}$ Cell Cardiol 1984; 16:385-8.

7 World Health Organisation. WHO criteria for the diagnosis of acute myocardial infarction. Proposal for the multinational of acute myocardial infarction. Proposal for the multinational
monitoring of trends and determinants in cardiovascular dismonitoring of trends and determinants in cardiovascular dis-
ease. Geneva: Cardiovascular Diseases Unit of WHO ease.

8 Langer A, Freeman MR, Armstrong PW. ST segment shift in unstable angina: pathophysiology and association with coronary anatomy and hospital outcome. $f \mathrm{Am}$ Coll Cardiol 1989;13:1495-502.

9 Mair J, Artner-Dworzak E, Lechleitner P, Morass B Smidt J, Wagner I, et al. Early diagnosis of acut myocardial infarction by a newly developed rapid immunoturbidimetric assay for myoglobin. $\mathrm{Br}$ Heart $\mathcal{F}$ 1992;68:462-8.

10 Brandt DR, Gates RC, Kathy KE, Forsythe CM, Korom $\mathrm{GK}$, Nitro AS, et al. Quantifying the MB isoenzyme of creatine kinase with the Abbott "IMx" immunoassay analyser. Clin Chem 1990;36:375-8.
11 Katus HA, Looser S, Hallermayer K, Remppis A, Scheffold T, Borgya A, et al. Development and in vitro characterization of a new immunoassay of cardiac troponin T. Clin Chem 1992;38:386-93.

12 Hofmann U, Rabitzsch G, Loester K, Handschack W, Noll F, Krause EG. Immunoenzymometric assay for the heart specific glycogen phosphorylase BB in human serum using monoclonal antibodies. Biomed Biochim Acta 1989;48:S132-6.

13 Rabitzsch G, Noll F, Hofmann U, Krause EG, Armbruster FP. Basal concentration of the isoenzyme BB of the glycogen phosphorylase $b$ in human blood. Clin Chim Acta 1993;214:109-11.

14 Hoberg $E$, Katus HA, Diederich KW, Kübler W. Myoglobin, creatine kinase-B isoenzyme, and myosin light chain release in patients with unstable angina pectoris. Eur Heart $\mathcal{7} 1987 ; 8: 989-94$.

15 Gerhardt W, Katus H, Ravkilde J, Hamm C, Jorgensen PJ, Peheim E, et al. S-troponin T in suspected ischemic myocardial injury compared with mass and catalytic concentrations of S-creatine kinase isoenzyme MB. Clin Chem 1991;37:1405-11.

16 Botker HE, Ravkilde J, Sogaard P, Jorgensen JP, Horder $M$, Thygesen $K$. Gradation of unstable angina on basis of a sensitive method for creatine kinase $\mathrm{MB}$ isoenzyme determination in serum. Br Heart f 1991;65:72-6.

17 Hamm CW, Ravkilde J, Gerhardt W, Jorgensen P, Peheim E, Ljungdahl L, et al. The prognostic value of serum troponin $\mathrm{T}$ in unstable angina. $N$ Engl 7 Med 1992; 327:146-50.

18 Entman ML, Kaniike K, Goldstein MA, Nelson TE, Bornet EP, Futch TW, et al. Association of glycogenolysis with cardiac sarcoplasmic reticulum. $\mathcal{J}$ Biol Chem 1976;251:3140-6.

19 Schulze W, Krause E-G, Wollenberger A. On the fate of glycogen phosphorylase in the ischaemic and infarcting glycogen phosphorylase in the ischaemic and infar

20 Entman ML, Bornet EP, Vanwickle WB, Goldstein MA, Schwartz A. Association of glycogenolysis with cardiac sarcoplasmic reticulum. II. Effect of glycogen depletion, deoxycholate solubilization and cardiac ischaemia: evidence for a phosphorylase kinase membrane complex. f Mol Cell Cardiol 1977;9:515-28.

21 Davies MJ, Thomas AC, Knapman PA, Hangartner JR. Intramyocardial platelet aggregation in patients with unstable angina suffering sudden ischemic cardiac death. Circulation 1986;73:418-27.

22 Falk E. Unstable angina with fatal outcome: dynamic coronary thrombosis leading to infarction and/or sudden death: autopsy evidence of recurrent mural thrombosis with peripheral embolization culminating in total vascular occlusion. Circulation 1985;71:699-708. 